ÁREA ABIERTA .Vo.12. $\mathrm{n}^{\circ}$ 1. MARZO 2012

http://dx.doi.org/10.5209/rev_ARAB.2012.v31.38969

Referencia: AA31.1203.157

"LA REPRESENTACIÓN DE LA FICCIÓN EN LA CUÑA PUBLICITARIA. PERSONAJES, CONTEXTOS Y OTROS ELEMENTOS NARRATIVOS"

AUTORA: Dra. MUELA MOLINA, Clara. Universidad Rey Juan Carlos

\title{
LA REPRESENTACIÓN DE LA FICCIÓN EN LA CUÑA PUBLICITARIA. PERSONAJES, CONTEXTOS Y OTROS ELEMENTOS NARRATIVOS 1
}

\author{
THE REPRESENTATION OF FICTION \\ IN RADIO SPOT. \\ CHARACTERS, CONTEXT AND OTHER \\ NARRATIVE ELEMENTS
}

\footnotetext{
1 Este artículo es el desarrollo de la comunicación de igual título presentada al Colloque, Radio et narration: le réenchantement?, Bruxelles, Université Catholique de Louvain, en noviembre de 2010.
} 


\title{
RESUMEN
}

Trabajos previos han demostrado que, en esencia, la publicidad radiofónica es realista e informativa de las características, propiedades y beneficios del producto anunciado desde una supuesta objetividad y con una pormenorizada enumeración. Sólo en el 9\% de los casos los creativos publicitarios eligen la ficción como modalidad narrativa para comunicar la oferta comercial al oyente. Y éste es el punto de partida para la investigación que se presenta, cuyos objetivos son identificar y cuantificar la presencia de dichos elementos en la cuña radiofónica. Los resultados del análisis de contenido de la muestra concluyen que en el 64,7\% de los casos, la voz del actor representa personajes de ficción muy familiares procedentes, sobre todo, de la literatura, el cine o la televisión y fácilmente reconocibles por el público objetivo. Asimismo, sólo en el 8,9\% de los anuncios, la trama representada se desarrolla en lugares imaginarios inexistentes en la realidad. La función descriptiva es la predominante en dos de los elementos del lenguaje radiofónico analizados: en el $30,8 \%$ de las cuñas, la música evoca objetos o elementos de la naturaleza mientras que en el $38,2 \%$ de los casos los efectos de sonido describen un escenario o reproducen un objeto.

Palabras clave: Narrativa. Radio. Publicidad. Ficción.

\begin{abstract}
Previous research has shown that radio advertising is essentially realistic and very informative about features, properties and benefits of the advertised product. But from a pretended objectivity and with a strong detailed list. In only 9\% of cases, copywriters choose fiction as a narrative form to communicate the commercial offer to the listener. This is the starting point for this research, whose aims are to identify and quantify the presence of these elements in the radio spot. The results of content analysis of the sample concluded that in $64,7 \%$ of advertisements, the actor uses very familiar voices of fictional characters from literature, film or television that are easily recognizable by the target audience. Only in 8,9\% of the advertisements the plot unfolds in imaginary places that do not exist in reality. In the two elements of radio language analyzed, the descriptive function is predominant: in $30,8 \%$ of radio spots, the music evokes objects or elements of nature while in $38,2 \%$ of cases, special sound effects describe a scene or reproduce an object.
\end{abstract}

Key words: Narrative. Radio. Advertising. Fiction. 


\section{Estado de LA CUEstión}

"No hay publicidad más maltratada -ni audiencia más maltratada- que la de la radio. Salvo alguna digna excepción, en ningún otro medio logra la publicidad ser tan insoportablemente aburrida, tan irritantemente repetitiva y tan irremediablemente (esto, esperemos que no) carente de ideas". Con esta contundencia resumía Alfonso Hernández (1998, p. 48), Director Creativo y Subdirector de TBWA Madrid, la situación de la publicidad radiofónica en España hace más de una década. Ha pasado bastante tiempo pero esas palabras siguen aún vigentes.

La publicidad a través de las ondas tienden a imitar el estilo característico de los programas radiofónicos recurriendo a la figura del locutor de noticias, el reportero de calle o el presentador de programas concursos o de musicales. (Muela Molina, 2010). Y la descripción del producto o servicio se realiza, por lo general, desde un estilo informativo esgrimiendo unos argumentos de venta desde una supuesta objetividad para comunicar la oferta comercial. Por tanto, la cuña publicitaria, sobre todo, apela a la razón y a la memoria del oyente solicitándole un sobreesfuerzo por procesar y aprender todas las características del producto y los innumerables datos de la oferta.

La ficción, las situaciones, los personajes o los contextos idealizados, donde el producto se oferta como un objeto de deseo, son elementos reservados para la televisión y los medios gráficos donde la creatividad se potencia a través de la imagen, el color o el movimiento consiguiendo un mayor impacto y notoriedad. Rodero Antón sostiene que "de esta manera, la radio continúa siendo el pariente pobre y con ello el más desconocido, el medio al que menos recursos se asignan, al que menos esfuerzo se dedica y el más olvidado desde el punto de vista de la investigación" (2008: 8).

La publicidad radiofónica no es un objeto de estudio de preferencia entre los investigadores. No obstante, aunque las investigaciones son escasas, cabe destacar la producción científica realizada desde el grupo catalán Publiradio centrado en la publicidad en el medio radio y en sus distintos elementos y factores. Así, los principales trabajos se han centrado en el análisis de la eficacia y en el proceso de planificación de las campañas publicitarias, han medido los efectos del mensaje en el receptor como la capacidad de recuerdo y la generación de imágenes mentales, o han tratado aspectos cualitativos del anuncio como el humor, la voz o la música.

En España hay varios trabajos como el de Muela Molina (2001) que realizó un análisis diacrónico y sincrónico de la creatividad publicitaria en la radio; el de Betés Rodríguez (2002) que hizo lo propio con el relato desde un enfoque semiótico; el de Alonso (2004) que se centró en el guión como instrumento de trabajo del creativo publicitario; el de Perona Páez (2007) que analizó los formatos 
y estilos publicitarios; y el de éste últlimo autor junto a Barbeito Veloso (2008) centrado en los elementos del lenguaje radiofónico de los anuncios emitidos en la franja de mayor audiencia del dial generalista.

Respecto a los estudios sobre la ficción como recurso narrativo, hemos encontrado referencias destacadas abordando dicho objeto de estudio desde su más amplia y detallada conceptualización (Currie, 1990); desde los actos de habla y la retórica (Adams, 1985); a través de investigación experimental para comprobar la influencia a la hora de procesar la información de la publicidad en televisión (Deighton et al., 1989) o medir el impacto de este tipo de anuncios en un televidente y en un lector (Boller, 1990). Por tanto, ninguna de las investigaciones realizadas en otros países han tratado la ficción publicitaria en el medio radio. No obstante, en España sí se ha publicado recientemente un trabajo (Arcos Foix y Perona Paez, 2011) donde se analiza este modelo narrativo según tres modalidades ficcionales que son: la dramatizada, la narrada y la ilustrativa o testimonial mediática.

Con estos precedentes y para este estudio, por tanto, se ha tomado como referencia la investigación de Muela Molina (2008) cuyos principales resultados revelaron que el $53 \%$ de la publicidad en radio representa la realidad cotidiana del público objetivo y que en el $21 \%$ de los casos es un locutor el que prescribe el producto en calidad de portavoz del anunciante. Así, 3 de cada 4 anuncios son realistas y sólo en el $9 \%$ de los casos la publicidad radiofónica recurre a la ficción. Ésta es, por tanto, la modalidad narrativa objeto de este trabajo cuyos objetivos son, por un lado, identificar los elementos con los que se narran las historias ficticias en la cuña publicitaria y, por otra parte, cuantificar su presencia.

\section{BASE METODOLÓGICA}

El objetivo de la investigación demanda centrar el análisis en la estrategia creativa (Joannis, 1996). Ésta forma parte del proceso de planificación de una campaña y está subordinada a la publicitaria, junto con la de medios, colaborando en la consecución de las metas generales de la empresa a través de sus dos componentes (Brochand y Lendrevie, 1993):

1) El contenido o fondo del mensaje -genéricamente denominado copy strategy- donde se decide lo que decir sobre el producto o servicio protagonista de la campaña -la promesa o el beneficio que el consumidor obtendrá de su usoy el público objetivo a quien va dirigido cada mensaje.

2) La organización del contenido o formatos creativos contempla los diferentes elementos narrativos a través de los que se comunica el contenido del mensaje publicitario de forma original -diferenciándose de la competencia- y eficaz -cumpliendo los objetivos comunicativos fijados por el anunciante en la estrategia-. 
Por tanto, partiendo de dicha descripción y delimitación conceptual, los elementos elegidos por los creativos publicitarios para comunicar el producto desde la ficción se adscriben al segundo componente de la estrategia creativa.

Muchos han sido los comunicólogos que han otorgado más importancia a la forma en cómo se dicen las cosas (Austin, 1982) que al propio mensaje en sí a la hora de influir en el receptor del mismo. Searle (1986) sostenía que, en los actos de habla del tipo ilocucionarios, la intencionalidad de la fuente es fundamental para que el receptor lleve a cabo las acciones pretendidas por el emisor, para lo cual, el lenguaje y la utilización correcta y precisa de los recursos lingüísticos son clave para la interacción social. La dimensión pragmática de la publicidad, al ser una comunicación interesada y al servicio de quien la paga, se basa en estos principios teóricos. Asimismo, su naturaleza esencialmente persuasiva (Reardon, 1983) le exige la búsqueda de unos argumentos, sean éstos racionales y/ o emocionales, pero siempre los más motivantes para el público objetivo; aquéllos que le muevan a adquirir el producto o contratar el servicio referente del anuncio y no el de otra marca competidora. Cabe añadir que, en radio, la palabra (Hernández Toribio, 2006) asume un protagonismo destacado en la redacción del guión radiofónico frente al resto de componentes del sonido; por tanto, es ésta la que aporta más información sobre el producto, la que añade credibilidad al mensaje (León, 1992) y describe el contenido de la oferta. Sin embargo, son otros elementos del lenguaje radiofónico como la música o los efectos de sonido los que sugieren imágenes mentales y activan la imaginación; son éstos los que más colaboran en la representación de la ficción en la publicidad del medio radio.

La concepción de este trabajo y los objetivos antes mencionados precisan técnicas cuantitativas de investigación, en concreto, el análisis de contenido. El formato publicitario elegido es la cuña publicitaria: mensajes pregrabados y emitidos, por lo general, a lo largo de la programación radiofónica en unos espacios comerciales junto con otros anuncios conformando lo que se denomina bloques publicitarios. La cuña es el formato publicitario más utilizado en radio con una duración media de 20 a 30 segundos cuyo contenido se estructura de forma similar permitiendo unificar el análisis. Es, por tanto, el mensaje persuasivo por excelencia; comprime en 20 segundos un texto descriptivo sobre el producto -la mayoría de las veces demasiado pormenorizado y poco argumentativo- a través de la música, voces, efectos de sonido y silencios.

La muestra se ha obtenido de las cuñas inscritas en los 6 Festivales publicitarios de San Sebastián2, sección de radio, ediciones de la XII a la XVII -ambas inclusive- que

\footnotetext{
2 Todas las cuñas inscritas en cada festival se pueden adquirir en unos discos compactos editados por la Asociación Española de Agencias de Publicidad. En concreto, el corpus analizado se ha obtenido de: CD Radio $12^{\circ}$ Festival Publicitario de San Sebastián, ASOCIACIÓN ESPAÑOLA DE AGENCIAS DE PUBLICIDAD, Madrid, 1997; CD Radio 13 Festival Publicitario de San Sebastián, ASOCIACIÓN ESPAÑOLA DE AGENCIAS DE PUBLICIDAD, Madrid, 1998; CD Radio 14 Festival Publicitario de San Sebastián, ASOCIACIÓN ESPAÑOLA DE AGENCIAS DE PUBLICIDAD, Madrid, 1999; CD Radio $15^{\circ}$ Festival Publicitario de San Sebastián, ASOCIACIÓN ESPAÑOLA DE AGENCIAS DE PUBLICIDAD, Madrid, 2000; CD Radio $16^{\circ}$ Festival Publicitario de San Sebastián, ASOCIACIÓN
} 
abarcan los años comprendidos entre 1997 a 2002 y donde sólo podían inscribirse campañas realizadas y emitidas en España ${ }^{3}$. Ésta ha sido utilizada como base para tesis doctorales (Alonso, 2003 publicada posteriormente en 2004) así como para otros trabajos de investigación (Muela Molina, 2008 y 2010). Del total de cuñas se seleccionaron las que incluían elementos y personajes fantásticos. Es decir, sólo serían objeto de análisis aquellos mensajes donde la ficción caracterizaba el universo de referencia ${ }^{4}$ entendiendo éste como el marco donde se desarrolla la historia principal, intervienen los personajes y se integra el producto objeto del mensaje. Así pues, el corpus final lo componen el 9\% del total de cuñas ( $n=72$ ) que han sido analizadas según las siguientes variables de la narrativa audiovisual (Moreno, 2003) y en el lenguaje radiofónico (Balsebre, 1994):

1. PERSONAJES. Los protagonistas del mensaje publicitario son descritos física y psicológicamente a través de la voz o la palabra. Los cuatro atributos que definen esta variable son los siguientes:

1) narrador que con un monólogo cuenta toda la historia;

2) actor que representa a personajes de ficción;

3) actor que representa a personajes reales;

4) combinación del monólogo del narrador con los diálogos de actores.

2. CONTEXTO. Los atributos que definen el escenario donde se desarrolla la acción pueden tratarse de:

1) lugares reales;

2) lugares ficticios;

3) ausencia de escenario;

3. MÚSICA. Los atributos para la variable música se han basado en la función que ejerce este elemento del lenguaje radiofónico según la clasificación de Beltrán Moner (1991):

1) descriptiva o imitativa: la música sugiere objetos o elementos naturales evocando imágenes mentales;

2) anímica: cuando lo que se pretende es provocar en el oyente determinados sentimientos y emociones, sensaciones o estados de ánimo;

3) ausencia de música;

4. EFECTOS DE SONIDO. Según Balsebre (1994), son cuatro las funciones que pueden desempeñar en el mensaje radiofónico y que se han tomado como atributos para este trabajo:

1) ambiental o descriptiva: recrean un escenario o evocan un objeto;

2) expresiva: transmiten un estado de ánimo, un sentimiento o situación afectiva, es decir, expresan una atmósfera psicológica, un ambiente;

3) narrativa: cuentan lo que sucede en un momento determinado de la historia o en una secuencia del anuncio;

ESPAÑOLA DE AGENCIAS DE PUBLICIDAD, Madrid, 2001; CD Radio $17^{\circ}$ Festival Publicitario de San Sebastián, ASOCIACIÓN ESPAÑOLA DE AGENCIAS DE PUBLICIDAD, Madrid, 2002.

3 A partir de 2003 se amplía el festival a los países de Latinoamérica y Portugal; así, para preservar las características de homogeneidad de la muestra, no se ha considerado analizar las últimas ediciones.

${ }^{4}$ Floch define universo de referencia como "el decorado [...], la gestión de los tiempos y de los espacios o de la distribución de los roles" (1993, p. 142). 
4) ornamental: es una simple cuestión estética, los efectos sólo acompañan a otros elementos en cuyo significado redundan;

5) ausencia de efectos de sonido;

Aunque la muestra elegida no es representativa desde el punto de vista estadístico, sí la entendemos significativa para cumplir con los objetivos planteados en esta investigación, es decir, describir los rasgos principales de la ficción publicitaria en la radio española. La codificación de las variables se realizó registrando la presencia o ausencia de cada atributo; también señalar que en los casos en que se escuchaba dos o más modalidades de la misma variable, se registró la que predominaba cualitativamente, no la que computaba una mayor presencia temporal.

\section{RESULTADOS}

\subsection{Los personajes: recuperados de la literatura, el cine y la televisión.}

Como puede observarse en la Figura 1 , en el $64,7 \%$ de los mensajes el actor representa personajes de ficción familiares y reconocibles por el público objetivo. Son abundantes los referentes literarios como Caín y Abel, Dios, Ulises, Los Reyes Magos o de obras cinematográficas como los mafiosos italianos tipo la saga de "EI Padrino". Una técnica muy utilizada para que el oyente identifique en un mensaje una historia o personaje de ficción es la utilización de los mismos dobladores de las películas o series de televisión. Estos profesionales prestan sus voces a los actores interpretando a los personajes más memorables de la pequeña o gran pantalla que el público objetivo identifica fácil y rápidamente a través de la voz, de la palabra o de sus rasgos vocales o verbales más característicos como, por ejemplo, el Doctor Hannibal Lecter de "El Silencio de los corderos" o Escarlata O'Hara, la protagonista de "Lo que el viento se llevó", como es el caso del siguiente anuncio5:

(música banda sonora de "Lo que el viento se llevó")

Escarlata O'Hara (imitadora): ¡A Dios pongo por testigo, a Dios pongo por testigo, que jamás volveré a pasar hambre!

Loc. Off: ¿̇Azul cielo? Zanussi colors. ¿̇De qué color quieres ver tu cocina cada mañana?

Y en el 11,8\% de los casos, las voces de los actores recrean personajes reales adscritos a la vida cotidiana como policías y reos, la hija con el padre, la madre con el hijo, el alumno con el maestro o la pareja -supuesto matrimonio, siempre convencional y heterosexual- como en la transcripción de esta otra cuña perteneciente a la misma campaña del ejemplo anteriorb:

\footnotetext{
${ }^{5}$ Cuña n ${ }^{\circ}$ 26, Zanussi Colors. CD Radio $15^{\circ}$ Festival Publicitario de San Sebastián, ASOCIACIÓN ESPAÑOLA DE AGENCIAS DE PUBLICIDAD, Madrid, 2000.

${ }^{6}$ Cuña $n^{\circ} 25$, Zanussi Colors. CD Radio $15^{\circ}$ Festival Publicitario de San Sebastián, ASOCIACIÓN

ESPAÑOLA DE AGENCIAS DE PUBLICIDAD, Madrid, 2000.
} 
Mujer muy enfadada: $\dot{2}$ Quieres el desayuno cariño? Pues toma tu desayuno (sfx: metralleta disparando y música emblemática de la película "Pulp Fiction" que bailaban los protagonistas)

Loc. Off: ¿̇Negro, muy negro? Zanussi colors. ¿¿De qué color quieres ver tu cocina cada mañana?

\section{Figura 1: Personajes representados a partir de la voz y frecuencia de aparición}

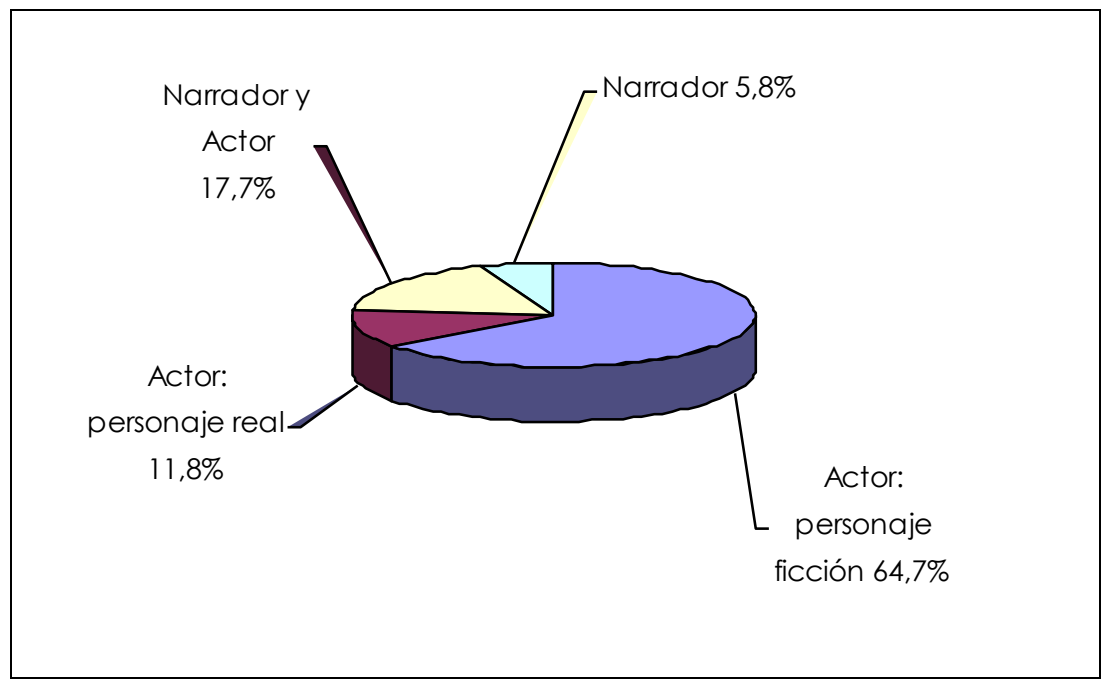

Fuente: Elaboración propia

Las cuñas donde se combina la figura del narrador, para poner en antecedentes al receptor, con los diálogos de los personajes que interpretan y desarrollan la historia suponen el 17,7\%; es el caso de un anuncio de coches donde una caperucita un tanto peculiar intenta huir del vampiro feroz -en este caso no es un lobo- en su coche dotado de un gran equipamiento en seguridad; dicha dramatización se combina con los resúmenes o introducciones que va realizando el narrador para situar al oyente en los hechos y escenas principales que van aconteciendo. Y sólo en el 5,8\% de los casos es un narrador quien en primera persona del singular cuenta su propia experiencia desde una personalidad ficticia; por ejemplo, en la siguiente cuña de una marca de todoterreno7, se recurre al protagonista de una serie infantil de televisión de los años 80 titulada "De los Apeninos a los Andes" que todos los domingos emitía las aventuras vividas Marco, un niño italiano acompañado de su inseparable mono Amedio, para encontrar a su madre que emigró a Argentina en busca de trabajo:

(Música de fondo italiana; voz locutor de hombre anciano y cansado) Loc: Mi nombre es Marco. Después de media vida buscando a mi mamá en Argentina tuve que vender mi mono Amedio a un taxidermista y me compré

7 Cuña $n^{\circ}$ 66, Galloper. CD Radio $13^{\circ}$ Festival Publicitario de San Sebastián, ASOCIACIÓN ESPAÑOLA DE AGENCIAS DE PUBLICIDAD, Madrid, 1998. 
un Galloper. Gracias a él, encontré su casa, pero ella también se había comprado un Galloper y había vuelto a Italia a buscarme. Yo volví también, pero mi mamá había regresado a Argentina. La última vez que la vi, fue cuando me iba (...)

\subsection{El contexto-escenario, más realidad que fantasía.}

Como se puede observar en la transcripción del ejemplo anterior, la narración del locutor no necesita un contexto donde tiene lugar la historia. Así, en algo menos de la mitad de las cuñas, en concreto, en el $41,7 \%$ se recrea un escenario donde se desarrolla la acción tal y como ilustra la Figura 2. Y de este porcentaje, el 32,8\% de los anuncios remite al oyente a lugares comunes, reales, como puede ser un hospital, una comisaría de policía o una prisión mientras que sólo en el 8,9\% de los casos, la trama representada se desarrolla en lugares ficticios, fantásticos, imaginarios como puede ser el arca de Noé.

\section{Figura 2: Tipos de contextos-escenarios representados y frecuencia de aparición}

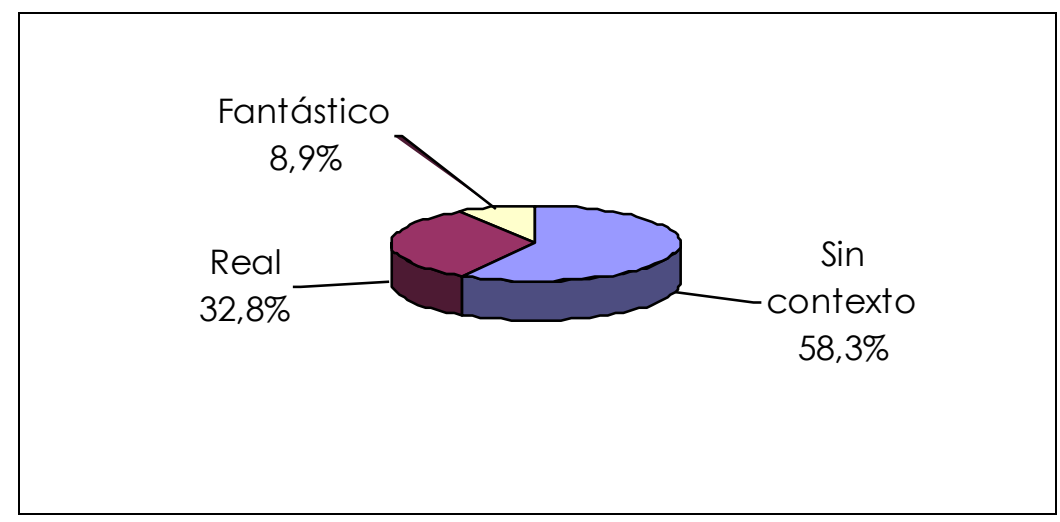

Fuente: Elaboración propia

En la mayoría de los anuncios, el paisaje sonoro se recrea a través de unos efectos de sonido fácilmente identificables audibles en esos lugares como los pitidos de aparatos electrónicos de un hospital, la máquina de escribir antigua y el teléfono en una comisaría, el ruido de los motores o el claxon de los coches en la calle, etc. Pero cuando se trata de un lugar imaginario, además de incluir ruidos característicos y familiares, se sitúa al oyente en ese escenario a través de la palabra. Es decir, cuando se le solicita al receptor del mensaje que deje volar su imaginación y viaje a un determinado lugar como, por ejemplo, al castillo de Drácula, además del rechinar agudo de la bisagra de una puerta muy pesada de madera, el locutor sitúa al oyente en ese escenario a través de la palabra advirtiendo de la entrada o de la estancia en la morada del vampiro como sucede en el extracto de la siguiente cuña8:

${ }^{8}$ Cuña n 25, Citroen Saxo. CD Radio $12^{\circ}$ Festival Publicitario de San Sebastián, ASOCIACIÓN ESPAÑOLA DE AGENCIAS DE PUBLICIDAD, Madrid, 1997. 
(sfx: trueno y fuerte tormenta acompañada de lluvia)

Loc: Transilvania, abril de 1997.

(sfx: aullido de lobo; sfx: trueno)

Reportero susurrando: Nos encontramos en el castillo del señor Conde para hacerle una breve entrevista. A ver si tenemos suerte porque parece que estaba echándose una siesta (sfx: puerta de hierro pesada se abre despacio). Parece que se ha despertado. Señor Conde, por favor.

Drácula anciano: Sí joven.

\subsection{La música, evocadora de paisajes y atmósferas.}

La música está presente también en el $42,6 \%$ de los anuncios tal y como muestra la Figura 3, con un claro predominio de su función descriptiva, el 30,8\%, por la que se pretende evocar objetos, elementos de la naturaleza o lugares concretos; sería el caso, por ejemplo, de la cerveza Coors que utilizó en una de sus campañas las famosas canciones del Western para invitar al oyente a viajar al árido Oeste Americano comunicando también, a través de la música, el origen geográfico del propio fabricante; aunque también son muy utilizadas las bandas sonoras de las películas más universales como "La guerra de las Galaxias" o el mítico "James Bond".

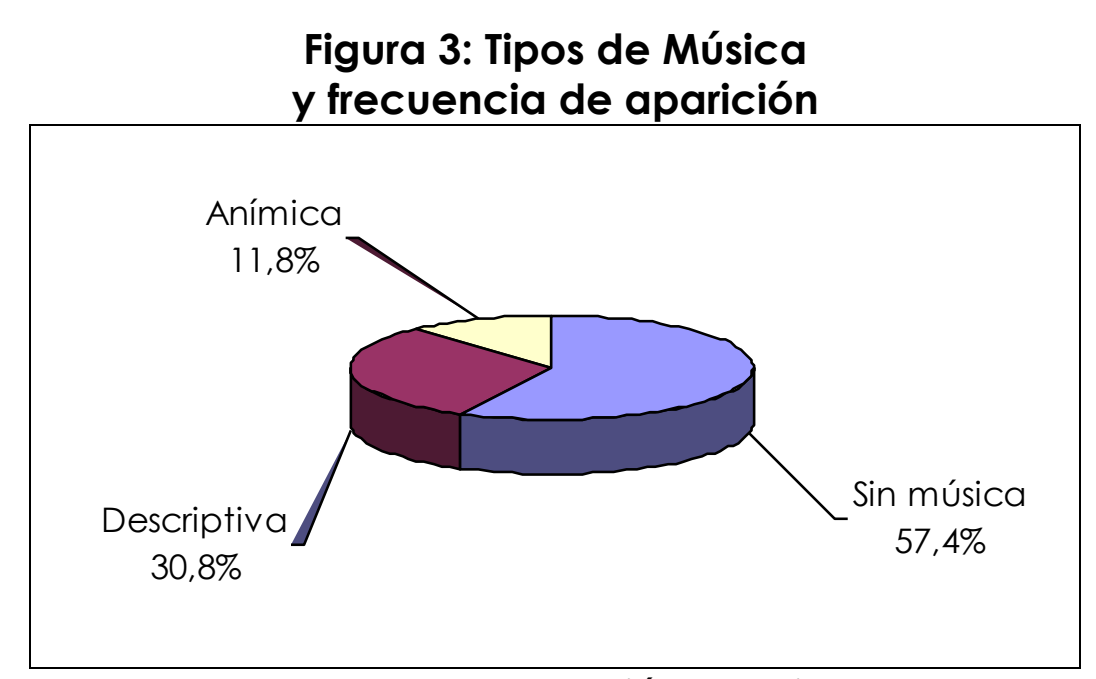

Fuente: Elaboración propia

Y, por otro lado, sólo en el $11,8 \%$ de las cuñas la música tiene como finalidad afectar el ánimo del oyente, provocarle determinados sentimientos, emociones o sensaciones como, por ejemplo, una música romántica para una escena de enamorados o una gregoriana para transmitir la paz celestial. Un ejemplo muy recurrente en la publicidad radiofónica donde se puede apreciar la función anímica de la música diferenciando, a su vez, las dos partes clave de la historia, es el del culebrón venezolano que combina también la figura del narrador con los diálogos de los actores, como en el siguiente9 ejemplo:

9 Cuña n 128, Sprite. CD Radio $13^{\circ}$ Festival Publicitario de San Sebastián, ASOCIACIÓN ESPAÑOLA 
(música de intriga de fondo)

Narrador: Sprite presenta la radionovela, Devuélveme el rosario de mi madre, capítulo 1724. Resumen del capítulo anterior: Rosa María Elena Eugenia, ha descubierto la traición de Darío Carlos Jesús y se dispone a enfrentarse a él. Venezolana: ¡Canalla, canalla, tres veces canalla! Anoche te vi bailando el mambo con Cara Fernanda y vi como la abrazabas. ¡Ella es mi hermana, desgraciado, traidor, eres horrible! Nunca te lo dije: tu aliento es fétido, te huelen los pies y eres el hombre más feo del mundo.

Venezolano: No llores más mi amor, mira lo que te he traído.

Venezolana: ¿̇Sprite?

(música más movida, tipo caribeña, salsa hasta el final de la cuña)

Venezolano: Sí, mi vida, toma, bebe.

Venezolana: ¡Ah (suspiro), mi príncipe! ¡Ay, cuánto me cuidas, qué generoso! Eres el hombre de mi vida. Quiero ser la madre de tus hijos.

\subsection{Los efectos de sonido: objetos y decorado.}

Los efectos de sonido son incluidos en el $77,9 \%$ de las cuñas. En concreto, y como puede verse en la Figura 4, en el 38,2\% de los casos describe un escenario 0 reproducen un objeto: el grito de Tarzán acompañado de los variados sonidos vegetales y animales de la jungla, el ambiente del restaurante con el bullicio de la gente y el choque de cubiertos en los platos, o el irritante ruido del tráfico. En el siguiente ejemplo puede observarse como algunos efectos de sonido cumplen esta función ${ }^{10}$ :

(sfx: puerta de madera que se abre)

Mujer: ¿2Pero qué oscura está la cocina? ¿ No parece un velatorio?

(sfx: grito mujer; sfx: golpe musical tensión psicológica; sfx: teléfono antiguo sonando; sfx: descolgar teléfono)

Policía: Policía, ¿̇dígame?

Mujer (voz distorsionada, tras el teléfono): Buenas noches. Le llamo del 18 centro izquierda de la Avenida Villaverde de los rojos. Se ha cometido un suicidio

(sfx: golpe musical tensión psicológica; sfx: sirena policía; sfx: timbre puerta; sfx: puerta se abre)

Policía: Inspector Bufete. ¿̇Es usted la señora Derma?

Mujer: Llámeme Paqui

(música tensión psicológica de fondo empieza y sigue)

Policía: ¿̇Cómo ocurrió todo?

(sfx: pasos 2 personas caminando a la vez hasta final cuña) 
Mujer: En la cocina. No escuché nada, ni el más mínimo ruido. Encendí la luz y la encontré ahorcada allí (sfx: golpe musical tensión psicológica), colgando del pómulo del cajón del aparador.

Policía: No se culpe señora, no es la primera cuchara que se suicida ni será la última.

(sfx: trueno que precede a tormenta)

Mujer: ¡Cómo quiere que no lo haga! Mire, yo tengo que reconocer que soy adicta al nuevo yogur para beber de Calypso, batido con pulpa fresca de lima y de limón, que para colmo es bajo en calorías y claro, hacía semanas que no la tocaba. Siempre la echaré de menos cuando veo su hueco en la cubertería.

Policía: No somos nadie, señora Derma

(música tensión psicológica de fondo va desapareciendo y termina; sfx: pasos 2 personas caminando a la vez desaparecen).

No obstante, en esta transcripción, tiene un mayor protagonismo la función narrativa de los efectos de sonido, como sucede en el 19,1\%, donde éstos sirven para contar parte, secuencias de la historia. Por otro lado, el ruido, entendido como un elemento decorativo que redunda en la palabra está presente en el $11,8 \%$ de los anuncios; no añade significado ni información adicional a la historia, sino que a modo de ornamentación ilustra la palabra. Y sólo en el 8,8\% de los casos, los efectos de sonido desempeñan una función expresiva a través de la que transmiten un estado de ánimo o un sentimiento, recrean una atmósfera, un ambiente como el tic-tac de un reloj de pared sin más acompañamiento que el silencio y alguna que otra palabra casi susurrada en primer plano.

Figura 4: Tipos y presencia de los efectos de sonido (SFX)

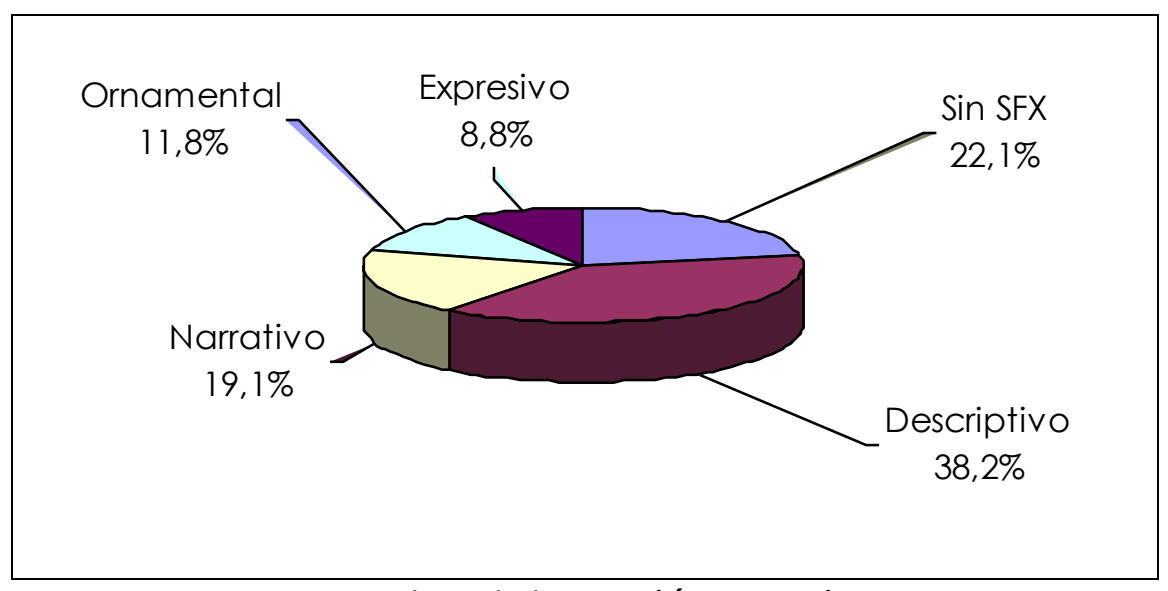

Fuente: Elaboración propia 


\section{CONCLUSIONES}

Cuando se trata de representar la ficción, la publicidad radiofónica se decanta por unos actores muy manidos que interpretan personajes fantásticos. Asimismo, son también recurrentes los más realistas, los que pertenecen a los grupos primarios como miembros de la familia, a los secundarios como amigos, compañeros de trabajo u otros como los dependientes, camareros, etc. Los personajes reales menos corrientes no suelen aparecer en escenas cotidianas del día a día protagonizando situaciones rutinarias en lugares habituales. De ahí que también los escenarios fantásticos sólo se evoquen en apenas una de cada 10 cuñas publicitarias; además, la sugerencia de los mismos se identifica mediante la palabra y no a través de otros recursos sonoros como los elementos del lenguaje radiofónico.

Que en más de la mitad de la muestra analizada no se incluya ningún tipo de música evidencia una infrautilización de este elemento a favor de la palabra que es la predominante y la que asume las funciones principales del mensaje. Es un resultado congruente con la fisionomía general de la comunicación persuasiva en radio: muy informativa y racional por lo que domina la palabra en detrimento de la emoción. Pero, ante todo, la radio es sonido, es sugerencia, y una de las principales funciones de la música es afectar el ánimo del oyente, influir en sus sentimientos y emociones, lo que sólo se pone en práctica por los creativos publicitarios en una de cada diez cuñas.

Los efectos de sonido también han de ser identificables con facilidad y rapidez por parte del oyente para colaborar en la consecución de los objetivos comunicativos fijados por el anunciante para su campaña. El público objetivo ha de recrear mentalmente el anuncio que se propone porque sino, en su esfuerzo cognitivo por interpretar el objeto referente de ese sonido, puede perder parte del mensaje que no podrá recuperar y puede, incluso, interferir en la comprensión de su contenido y de lo que se está comunicando sobre el producto. No obstante, se podría apostar más por la función expresiva del ruido con la que transmitir, no ya la imagen de un objeto, sino un ambiente, una atmósfera a la historia. Pero para ello sería necesario que los creativos publicitarios dedicaran bastante más esfuerzo a pensar en la publicidad para radio; pero esto supondría para muchos una mayor complejidad a la hora de trabajar en un medio que no dominan, que les llevaría mucho tiempo y que no resultaría rentable para la agencia.

Por esta misma razón asumimos, ya desde el principio del trabajo, que esta muestra no es representativa aunque sí significativa para cumplir nuestros objetivos, ya que si fuera así, la realidad y los porcentajes todavía serían más reducidos. En este sentido, todavía queda mucho por hacer para demostrar el verdadero potencial que tiene la radio como medio publicitario y evidenciar que está totalmente desaprovechado. Y esta situación repetida tantos años, denunciada décadas incluso, necesitaría una concepción estratégica totalmente diferente del propio sector, tanto para planificar las campañas como la creatividad. Futuras 
investigaciones podrían intentar demostrar empíricamente la eficacia de este tipo de anuncios frente a los más realistas, tanto en su efecto en el receptor como en la forma de integrarlo en la programación. También podría realizarse estudios comparativos entre diferentes países para comprobar si se trata de un problema generalizado del medio o de nuestro país. Y, por último, el efecto de los elementos del lenguaje radiofónico se podría testar en cuñas con distintos recursos narrativos.

\section{REFERENCIAS BIBLIOGRÁFICAS}

ADAMS, Jon-K. Pragmatics and fiction, Philadelphia, John Benjamins B.V., 1985.

ALONSO, Carmen $M^{a}$. El canto de las sirenas. Comunicación y persuasión en la publicidad radiofónica, Publicaciones de la Universidad Pontificia de Salamanca, Salamanca, 2004.

ARCOS FOIX, Nuria; PERONA PAEZ, Juan J. "Modalidades narrativas, usos y presencia de la ficción como recurso creativo en la publicidad radiofónica", Anàlisi, 43 (2011), pp. 1-19.

AUSTIN, John L. Cómo hacer cosas con palabras. Palabras y acciones, Paidós, Barcelona, 1982.

BALSEBRE, Armand. El lenguaje radiofónico, Cátedra, Madrid, 1994.

BELTRÁN MONER, Rafael. Ambientación musical, 2ª ed., IORTV, Madrid, 1991.

BETÉS RODRÍGUEZ, Kety. El sonido de la persuasión: relatos publicitarios en radio, Servicio de Publicaciones, Fundación Universitaria San Pablo-CEU, Valencia, 2002.

BOLLER, Gregory W. "The vicissitudes of product experience: 'Songs of our consuming selves' in drama ads", Advances in consumer research, 17 (1990), pp. 621-626.

BROCHAND, Bernard; LENDREVIE, Jacques. Le Publicitor, 4èmeed., Dalloz, Paris, 1993.

CURRIE, Gregory. The nature of fiction, Cambridge University Press, Cambridge, 1990.

DEIGHTON, John; ROMER, Daniel; MCQUEEN, Josh. "Using drama to persuade", Journal of Consumer Research, vol. 16, 3 (1989), pp. 335-343.

FLOCH, Jean-Marie. Semiótica, marketing y comunicación/ Bajo los signos, las estrategias, Paidós, Barcelona, 1993, p. 142. 
HERNÁNDEZ, Alfonso: "La radio no tiene quien la escriba", Anuncios, n 810 (1998), p. 48.

HERNÁNDEZ TORIBIO, Ma Isabel.: El poder de la palabra en la publicidad de radio, Octaedro, Barcelona, 2006.

JOANNIS, Henri. La creación publicitaria desde la estrategia de marketing, Deusto, Bilbao, 1996.

LEÓN, José Luis. Persuasión de masas. Psicología y efectos de las comunicaciones sociopolíticas y comerciales, Deusto, Bilbao, 1992.

MORENO, Isidro. Narrativa audiovisual publicitaria, Paidós, Barcelona, 2003.

MUELA MOLINA, Clara. La publicidad radiofónica en España. Análisis creativo de sus mensajes, Ediciones Internacionales Universitarias, Madrid, 2001.

MUELA MOLINA, Clara: "La representación de la realidad en la cuña publicitaria". Comunicación y Sociedad, 21, 2 (2008), pp. 115-139.

MUELA MOLINA, Clara: "La representación de los géneros informativos en la publicidad radiofónica", Sphera Pública, 10 (2010), pp. 183-199.

PERONA PAEZ, Juan José: "Formatos y estilos publicitarios en el prime-time radiofónico español: infrautilización y sequía de ideas", Zer, 23 (2007), pp. 219-242.

PERONA PAEZ, Juan José y BARBEITO VELOSO, María Luz: "El lenguaje radiofónico en la publicidad del prime time generalista. Los anuncios en la 'radio de las estrellas', Telos, 77 (2008), pp. 115-124.

REARDON, Kathleen K. La persuasión en comunicación/ Teoría y contexto, Paidós, Barcelona, 1983.

RODERO ANTÓN, Emma. "Publicidad en radio: Publicidad, sí, pero no radiofónica", Área Abierta, n²0 (2008), en:

http://revistas.ucm.es/inf/15788393/articulos/ARAB0808230001E.PDF

(Fecha de consulta Diciembre 2010).

SEARLE, John. Actos de habla, Cátedra, Madrid, 1986. 